\title{
Inflorescence and Flower Development in Chinese Ixora
}

\author{
Li-Yun Chen ${ }^{1}$ \\ Department of Plant Industry, National Pingtung University of Science and Technology, Pingtung, \\ Taiwan, Republic of China \\ Chien-Young Chu and Min-Chang Huang \\ Department of Horticulture, National Chung-Hsing University, Taichung, Taiwan, Republic of China
}

Additional Index words. Ixora chinensis, primordia, anthesis, flowering, cyme

\begin{abstract}
Experiments were conducted on 6-month-old chinese ixora (Ixora chinensis Lam.) from February 1999 to April 2000. Floral development was studied with scanning electron microscopy (SEM) to determine the flowering sequences. Morphological characters were used to clarify the stages of flowering processes. The time of organogenesis and flowering arrangement was established through field observations. Floral evocation occurred in early September, floral initiation occurred in the middle of September and floral differentiation began in late September. A distinctly convex apex with bracts around the shoulder indicated the beginning of reproductive development. Subsequently, primary inflorescence axes were observed and differentiated into secondary, tertiary, and quaternary inflorescence axes consecutively in about one and a half months. Once the terminal apex reached the inflorescence bud stage, it would flower without abortion, and this may be assessed as no return. The sepals, petals, stamens, and pistil were well developed thereafter and anthesis was achieved in January through March in the following year. The observation of floral differentiation sequences and investigation of floret arrangement made it certain that chinese ixora had cymose inflorescence (cyme), but not corymb. A quadratic equation was established to predict floret number from the differentiation level (a quantitative description of differentiation stage) of a developed inflorescence.
\end{abstract}

Chinese ixora (Ixora chinensis) is native to South China and Malaya (Graf, 1985, 1986; Liu, 1962; Liu et al., 1988; Whistler, 2000). It was introduced to Taiwan from Canton, China in 1690 (Chen and $\mathrm{Hu}, 1976$ ) as a garden flowering shrub. Chinese ixora because of its attractive orange-red flowers and rich green foliage on stiff stems displays a good harmony for flower arrangement. In addition, chinese ixora has a longer vase life than other Ixora species which makes it a good cut flower (Chen and Huang, 1996). When dwarfed with growth retardants, e.g., paclobutrazol, to keep plants in balance with pot size, chinese ixora can be an excellent flowering pot plant (Shillo and Tsook,1989). Mild temperatures between 10 to $20{ }^{\circ} \mathrm{C}$ promote flower initiation, while a high temperature around $30^{\circ} \mathrm{C}$ maintains chinese ixora in a vegetative state (Sakai and Higuchi, 1980; Shillo and Tsook, 1989). However, there is little information on floral morphology of chinese ixora and it is debatable whether its infloresence is a corymb (Graf. 1985, 1986; Liu, 1962; Shillo and Tsook, 1989) or a cyme (Liu et al., 1988).

In this paper, floral development in greenhouse-grown chinese ixora plants was studied by scanning electron microscopy (SEM), and the floret arrangement was established through field investigation. Also, the chronology of vegetative and reproductive development was established to clearly understand the effects of environmental conditions on floral bud development.

\section{Materials and Methods}

Chinese ixora plants were propagated by single-node cuttings, with one expanded leaf pair in February 1999. The base was treated with $0.1 \%$ indolebutyric acid (IBA) in talc, and inserted in

Received for publication 9 Jan. 2002. Accepted for publication 4 Oct. 2002. The authors acknowledge the great appreciation for the assistance of SEM by T.M. Shen, M.J. Lee and B.H. Su and manuscript review by P.Y. Lai, G.S. Chen and F.C. Chen. This research was supported in part by grants from Council of Agriculture, Executive Yuan, Taiwan, R.O.C.

${ }^{1}$ Corresponding author; e-mail lychen@mail.npust.edu.tw.
$27 \mathrm{~cm}^{3}$ Oasis Rootcubes (ASPAC Floral Products, Kowloon, Hong Kong, China). Then, the cubes were placed in 70-cell flats $(56 \times 36 \times 4.5 \mathrm{~cm})$ and placed in a polyethylene-panel covered house with intermittent mist set for $10 \mathrm{sec}$ every $30 \mathrm{~min}$ in February and March and $10 \mathrm{~s}$ every $20 \mathrm{~min}$ in April through September from 0800 to 1800 HR daily.

After 8 weeks, rooted cuttings were potted in plastic $9 \mathrm{~cm}$ pots $(350 \mathrm{~mL})$ and placed on benches at the experimental farm of the National Pingtung University of Science and Technology (NPUST), Pingtung, Taiwan $\left(22^{\circ} 39^{\prime} \mathrm{N}, 130^{\circ} 36^{\prime} \mathrm{E}\right)$ under natural conditions. After another 4 weeks, plants were transplanted into 13-cm-diameter (1000-mL) plastic pots until plants developed 89 pairs of expanded leaves. The potting medium consisted of 2 peat : 2 coarse sand : 1 compost (by volume). Plants were fertilized weekly with 20N-8.9P-16.6K soluble fertilizer (Pokon, Pokon and Chrysal B.V., Holland) at an $\mathrm{N}$ rate of $200 \mathrm{mg} \cdot \mathrm{L}^{-1}$. Pesticide applications were made occasionally to control mealybugs.

Ten terminal buds were sampled at biweekly intervals from July to September 1999, and weekly from October 1999 through February 2000. The outer and inner stipules and leaflets were carefully removed under a binocular microscope to expose the shoot apex. Then, the meristems were excised and placed in a $2.5 \%$ glutaraldehyde solution (in $0.1 \mathrm{~m}$ phosphate buffer, $\mathrm{pH} 7.0$ ) for $2 \mathrm{~h}$. The specimens were rinsed with $0.1 \mathrm{M}$ phosphate buffer three times (15 min each) and followed by a series of dehydration in ethanol $(30 \%, 50 \%, 70 \%, 80 \%, 90 \%$, and $95 \%)$ for $10 \mathrm{~min}$ each. After three changes in $100 \%$ ethanol, the samples were dried with a critical point dryer (HCP-2 Hitachi, Tokyo, Japan). Samples were then mounted on aluminum stubs and coated with $\mathrm{Au}$ of 20 to $40 \mathrm{~nm}$ in thickness by an ion coater (IB-2, Eiko Engineering Co., Ltd, Sinku Kiko, Japan). All samples were viewed and photographed with the SEM (S-2400, Hitachi, Tokyo, Japan) at an accelerating voltage of $15 \mathrm{kV}$.

An additional 20 plants of similar size were observed for 
Table 1. Sequence of events in flowering processes of chinese ixora.

\begin{tabular}{ll}
\hline \hline Stage & Apex development (corresponding figures) \\
\hline 1 & Vegetative stage (Fig. 2A and B) \\
2 & Floral evocation (Fig. 2C) \\
3 & Floral initiation (Fig. 2D) \\
4 & Floral differentiation. Bract primordia visible under SEM (Fig. 2E) \\
5 & Floral differentiation. Apex swelled and a little dome-shaped (Fig. 2F); dome-shaped apex obvious (Fig. 2G) \\
6 & Three primary inflorescence axis primordia visible (Fig. 2H; Fig. 3A) \\
7 & Secondary inflorescence axis primordia differentiated. Sometimes axillary flower bud primordia visible. (Fig. 3B; Fig. 4A and B) \\
8 & Tertiary inflorescence axis primordia differentiated (Fig. 3C; Fig. 4C), very light orange red color on bracts \\
9 & Quaternary inflorescence axis primordia differentiated (Fig. 3D; Fig. 4D), bracts showed light orange red color \\
10 & One to three florets formed on each quaternary inflorescence axis (Fig. 4E) \\
11 & Floret development. Sepal, petal, stamen and pistil primordia well developed accordingly (Fig. 4F). Bracts showed orange red color \\
12 & Anthesis. Inflorescence elongated and florets bloomed sequentially (Fig. 4G and H). Sepals and petals showed orange red color \\
\hline
\end{tabular}

anthesis. Plants were considered to have reached anthesis when the first floret bloomed. The experiment was terminated on 10 Apr. 2000 when all plants had achieved anthesis. Temperature records were collected by a weather station close to the field plot and the $10-\mathrm{d}$ means of maximum and minimum temperatures were calculated.

Meanwhile, 100 inflorescences were randomly harvested from two-year-old plants grown in the field to analyze the floret arrangement and determine the relationship between the differentiation level and the number of florets.

\section{Results}

Initiation of chinese ixora floral bud was not a simple or rapid process. The sequence of events in flowering processes could be divided into 12 stages (Table 1). The terminal bud of 6-month-old chinese ixora was in vegetative phase in late August when air temperature was still high (Fig. 1). The apex was completely covered by the uppermost pair of leaf primordia and trichomes, which made the apex difficult to observe until the outside layer of trichomes was removed (Stage 1, Fig. 2A). After the upper pair of leaf primordia separated and surrounding trichomes were removed, the apex could be seen clearly under the SEM (Stage 1, Fig. 2B). When the air temperature began to decrease in early September (Fig. 1), floral evocation started. The bud was $\approx 0.4$ $\mathrm{mm}$ in diameter, the apex broadened, and separation of the upper leaf pair primordia was obvious (Stage 2, Fig. 2C). On 11 Sept., the apex was still flat but broadened to $\approx 0.5 \mathrm{~mm}$ in diameter and the upper pair of leaf primordia separated further (Stage 3, Fig. 2D). Buds examined on 25 Sept. showed that differentiation had occurred in the apical meristems and bract primordia were visible under the SEM (Stage 4, Fig. 2E).

On 2 and 13 Oct., apices were dome-shaped and distinctly raised. This was an indication of changeover from a vegetative to a reproductive state (Stage 5; Fig. $2 \mathrm{~F}$ and $\mathrm{G}$ ). Thereafter, the apical meristem developed into three primary inflorescence axes (one central and two side axes) (Stage 6, Fig. 2H; Fig. 3A) as the ambient temperature gradually decreased by mid-October (Fig. 1).

Floral buds sampled in the field from 30 Oct. through 10 Nov., were swollen and colored. In about 1 week, each primary inflorescence axis differentiated into three secondary axes (a total of nine secondary axes developed; Stage 7, Fig. 3B, Fig. 4A and B). On 20 Nov., with the bud about $1.5 \mathrm{~mm}$ in diameter, each secondary inflorescence axis differentiated into three tertiary axes (a total of 27 tertiary axes, Fig. 3C; Fig. 4C), and the bracts displayed a very light orange-red color (Stage 8). When the apex differentiated to this stage, the primordia continued to develop as an inflorescence and would bloom accordingly without abortion. This may be assessed as a no return stage.

The differentiation of the tertiary inflorescence axis was completed around 27 Nov. when the bud was about $2.0 \mathrm{~mm}$ in diameter. Then, each tertiary axis, especially the nine central ones, differentiated into three quaternary inflorescence axes (Fig. 3D; Fig. 4D). However, each of the nine tertiary axes on both sides differentiated into one to three floret primordia and flowered directly. The bracts were light orange-red in color at this time (Stage 9). Buds examined on 4 Dec., with a diameter of about 3.0 $\mathrm{mm}$, possessed one to three floret primordia on the quaternary axes (Stage 10, Fig. 4E). On 11 Dec., the bud was about $5.0 \mathrm{~mm}$ in diameter, and sepal, petal, stamen, and pistil primordia were well developed (Fig. 4F) with orange-red bracts (Stage 11). In early January, the inflorescence elongated, and by this time the sepals and petals of each floret showed an orange red color. Bloom occurred soon afterward (Stage 12, Fig. 4G and $\mathrm{H}$ ).

An additional field study on anthesis showed that inflorescence buds were visible in the field at the end of November, and that anthesis occurred in mid-January. Among the twenty 1.5year-old plants investigated, $\approx 55 \%$ of the plants flowered by January, $70 \%$ by February, $95 \%$ by March, and all plants flowered by 10 April (Fig. 5).

The floret arrangement observed in this experiment showed that chinese ixora's inflorescence theoretically would have 81 florets if all of the florets on quaternary axes had developed fully without abortion (Fig. 6A). Sometimes, inflorescences had $<81$ florets due to abortion for unknown reasons (Fig. 6B). While the

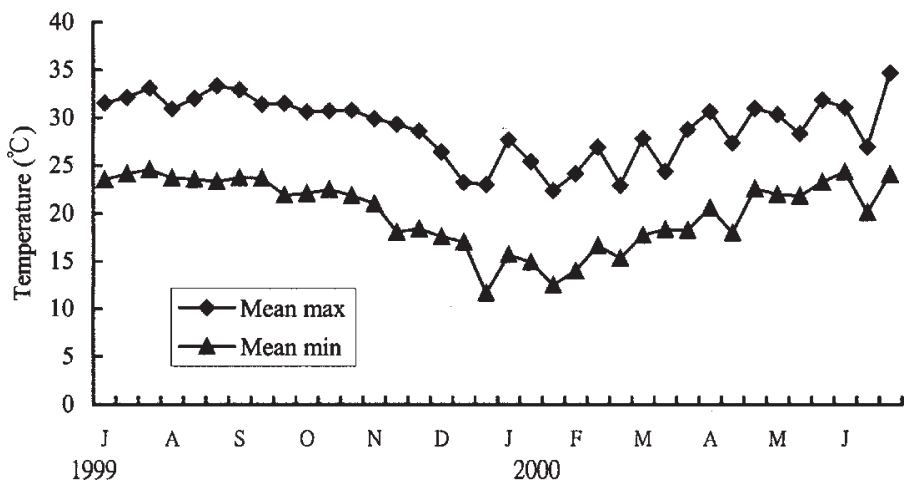

Fig. 1. The mean 10-d maximum and minimum temperatures in NPUST from July 1999 to June 2000 

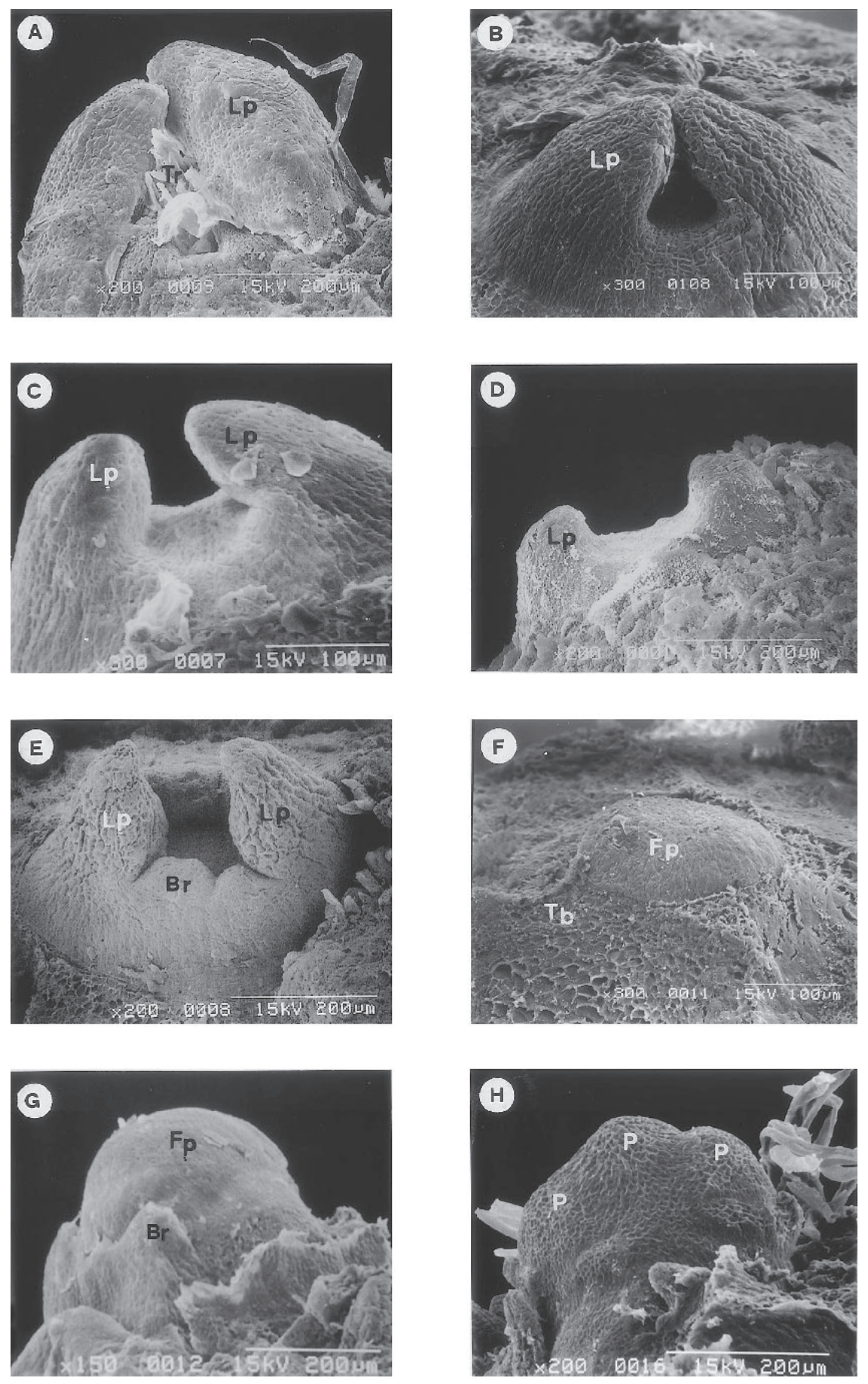

quaternary axes continued to differentiate into pentamerous floret primordia, especially the central ones, inflorescences could have more than 81 florets (Fig. 6C), particularly the ones that bloomed in the spring. In our study, the relationship between differentiation stage and floret percentage distribution was investigated, the result showed that $\approx 65 \%$ of the flowers on the central

Fig. 3. Schematic diagrams of the sequence of inflorescence development. (A) Three primary inflorescence axis primordia $(\mathrm{P})$ differentiated on the terminal bud. (B) Each primary inflorescence axis primordium differentiated into three secondary inflorescence axis promordia (S). (C) Each secondary inflorescence axis primordium differentiated into three tertiary inflorescence axis primordia (T). (D) Each tertiary inflorescence axis primordium differentiated into one to three quaternary floret primordia or inflorescence axis primordia $(\mathrm{Q})$, depending on the axis site.
A

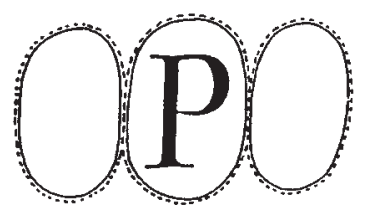

c

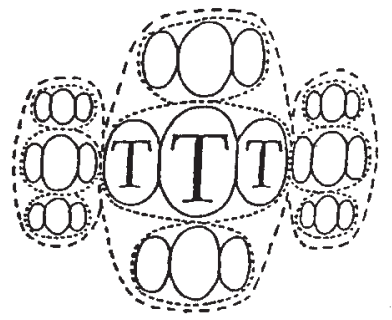

Fig. 2. Scanning electron micrographs of chinese ixora shoot apices from vegetative stage to the stage of primary inflorescence axis development. (A and $\mathbf{B}$ ) Vegetative tips, sampled on 7 and 21 Aug., apex completely covered by the upper leaf pair primordia and trichomes; in Fig. 2B. upper leaf pair primordia separating a little. (C) Floral evocation, sampled on 4 Sept., apex broadened, upper leaf pair primordia obviously separated. (D) Floral initiation, sampled on 11 Sept., apex broadened more and flattened. $(\mathbf{E}$ to $\mathbf{H})$ Floral differentiation, sampled on 25 Sept. and 2, 13, and 23 Oct., respectively; (E) bract primordia visible; (F) apex swelled and a little dome-shaped; (G) domeshaped apex (floral primordium) obvious and bract primordia clearly visible, the bract on the right was intentionally cut away; $(\mathbf{H})$ one central and two side primary inflorescence axis primordia visible. $\mathrm{Lp}=$ leaf primordia, $\mathrm{Tr}=$ trichome, $\mathrm{Br}=$ bract, $\mathrm{Fp}=$ floral primordium, $\mathrm{P}=$ primary inflorescence axis primordia, $\mathrm{Tb}=$ trace of bract.

axis had differentiated to quaternary stage while $77 \%$ of the flowers were at the tertiary stage on the side axes (Fig.7).

In the meantime, by observing the differentiation stage of the central and two side axes, we concluded that the floret number could be inferred from the differentiation level (a quantitative description of the differentiation stage). Since we learned from SEM observations that each inflorescence axis normally differentiated into three axes, the total floret number of an inflorescence could be expressed as an exponential function with a base of three, and the exponent was defined as the differentiation level $(\mathrm{y}=$ $20.4 x^{2}-43.4 x$, where $x$ represents differentiation level and $\mathrm{y}$ represents total floret number of one inflorescence). The statistical relationship between the differentiation level and total floret number was studied on central axis and shown in Fig. 8.

\section{Discussion}

The definition of the initiation of floral primordia as well as the development of these primordia into mature inflorescences until anthesis followed those proposed by Bernier et al. (1981a, 1981b) and Kinet et al.
B

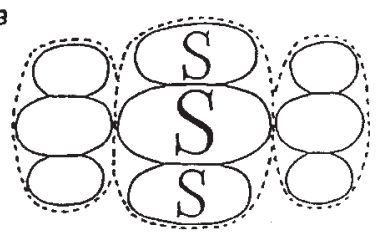

D

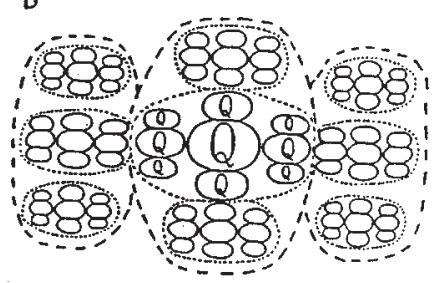



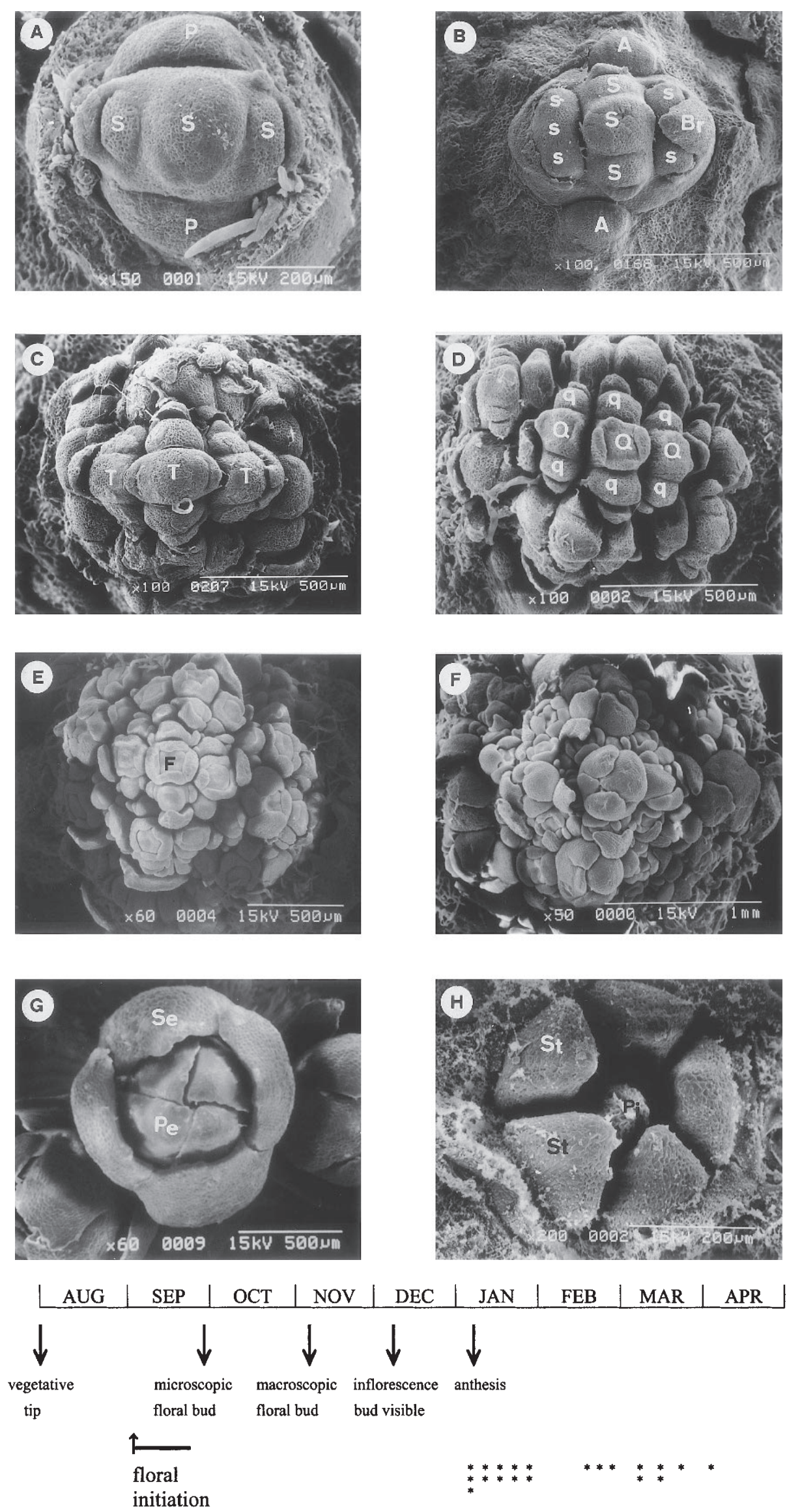

(11)
(5) (1)
Fig. 4. Scanning electron micrographs of chinese ixora from the stage of secondary inflorescence axis to the stage of anthesis. (A) Floral differentiation, sampled on 30 Oct., one primary axis differentiated into three secondary axes. (B to $\mathbf{F}$ ) Inflorescence buds, sampled on 10, 20, 27 Nov., and 4, 11 Dec. (B) Nine secondary and two axillary axes visible. (C) One secondary differentiated into three tertiary axes. (D) One tertiary differentiated into three quaternary axes. (E) Floret primordia formed on the quaternary axes. (F) Floret development, ready to bloom. (G) Sepals and petals of individual floret clearly visible. (H) Five stamen (normally four) and one pistil primordia visible. $\mathrm{P}=$ primary inflorescence axis primordium, $\mathrm{S}=$ secondary inflorescence axis primordium, $\mathrm{T}=$ tertiary inflorescence axis primordium, $\mathrm{Q}=$ quaternary inflorescence axis primordium, $\mathrm{A}=$ axillary inflorescence axis primordium, $\mathrm{F}=$ floret primordium, $\mathrm{Se}=$ sepal primordium, $\mathrm{Pe}=$ petal primordium, $\mathrm{St}=$ stamen primordium, $\mathrm{Pi}=$ pistil primordium.

(1985). Litlere and Stromme (1975) characterized the flower development of hydrangea, which has cymose inflorescence, into 7 stages with schematic diagrams. Based on our observation on the floral differentiation of chinese ixora with SEM micrographs, we concluded that the flowering processes could be divided into 12 different stages, which could help us to understand the developing sequence of flowering processes.

Liu (1962) and Shillo and Tsook (1989) stated that the tubular flowers of chinese ixora were arranged in dense corymb which was defined by Griffiths (1994), Kinet et al. (1985) and Porter (1967) as an indeterminate flat-topped or convex inflorescence where the outer florets opened first. However, our observation showed that chinese ixora has a decussate phyllotaxy and the differentiation of its inflorescence axis primordia occurs as a continuation of this decussate arrangement. In each step of differentiation from the primary axis to the quaternary axis, the latter differentiates perpendicularly to the former and florets in the middle bloom first. The flowering sequence clearly indicates that chinese ixora's florets are arranged as a determinate inflorescence, and the central floret opens first. Such a structure was defined as a type of cymose inflorescence or a cyme (Griffiths, 1994; Porter, 1967). In our study, we noticed that the central axes differentiated faster than the ones on the side which could explain why the central axes always had more florets than the sides.

Fig. 5. Chronology of reproductive bud development in Ixora chinensis in Pingtung, southern Taiwan. Microscopic reproductive event refers to obvious floral bud differentiation, as evidenced by swollen and dome-shaped apex under microscope (stages in Fig. 2F and G); macroscopic flowering event refers to visible swelling of bud to the naked eye in the field (stages in Fig. 4A-C). Asterisks refer to the number of flowering plants over a total of 20 plants investigated. 
A

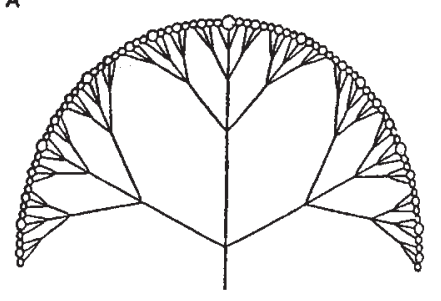

B

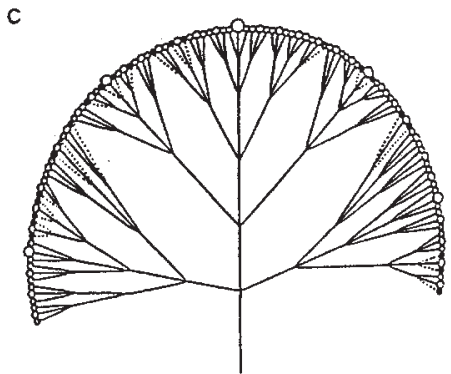

Fig.6. Flowering patterns frequently occurred on chinese ixora. (A) Theoretical standard flowering pattern is that all florets bloom on the quaternary axes without abortion. $(\mathrm{N}=81)$. (B) Some directly flowered on the tertiary axes, most of the ones at two sides $(81>\mathrm{N}>27$, in this diagram, $\mathrm{N}=41)$. (C) Some differentiated into pentamerous axes and flowered on them. This usually occurred on the nine central quaternary axes $(243>\mathrm{N}>81$, in this diagram, $\mathrm{N}$ =91). Different circle sizes represent flowering sequences; the larger, the earlier. Circles with cross inside and dotted lines beneath represent aborted florets. $\mathrm{N}=$ number of florets.

Theoretically, each inflorescence should have $81\left(3^{4}=81\right)$ florets (Fig. 6A). However, the actual number of florets could be less (Fig. 6B) or more (Fig. 6C) than 81. If florets formed on the tertiary axes or some florets on the quaternary axes aborted, the total number would be less than 81 (Figs. 6B and 8). On the contrary, if the quaternary axes continued to differentiate into pentamerous axes, there would be more than 81 florets developed on an inflorescence (Figs. 6C and 8). The number of total florets could be predicted by a quadratic function of the differentiation level on central axis $\left(y=20.4 x^{2}-43.4 x\right.$, where $x$ represents differentiation level, y represents total floret number) (Fig. 8).

The floral initiation of chinese ixora was promoted at temperatures between 10 and $20{ }^{\circ} \mathrm{C}$, and inhibited at $30{ }^{\circ} \mathrm{C}$ (Sakai and Higuchi, 1980; Shillo and Tsook, 1989). Morioka et al. (1989) also mentioned that the floral bud formation and flowering time of chinese ixora were promoted by an increase in temperature when plants were transferred from $7{ }^{\circ} \mathrm{C}$ to $7,10,15$, and $20^{\circ} \mathrm{C}$, respectively. During our experiment, the mean day/night temperatures were $32.3 \pm 1.8 / 24.1 \pm 0.8^{\circ} \mathrm{C}$ in July and $32.1 \pm 2.7 / 23.5$ $\pm 0.5{ }^{\circ} \mathrm{C}$ in August (Fig. 1). The plants were completely in a vegetative state at those time (Fig. 5) which was in agreement with previous studies (Sakai and Higuchi, 1980; Shillo and Tsook, 1989). When the night temperature gradually decreased to less than $24^{\circ} \mathrm{C}$ in September, floral initiation commenced (Figs. 1 and 2D). In a favorable environment for floral differentiation, e.g., night temperature lower than $22^{\circ} \mathrm{C}$ and light intensity above $185 \mu \mathrm{mol} \cdot \mathrm{m}^{-2} \cdot \mathrm{s}^{-1}$ (data not presented), the apices will differentiate into primary, secondary, tertiary and even quaternary inflorescence axes as shown in Figs. 2H and 4A-D and the florets will differentiate and develop. Then the whole inflorescence will elongate and anthesis will occur. The whole process (from floral

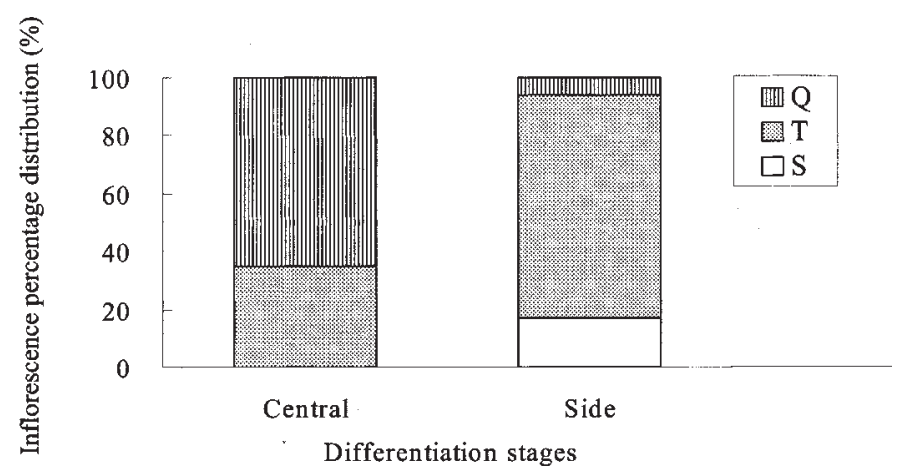

Fig.7. Inflorescence percentage distribution of differentiation stages on central and side axes over 100 inflorescences investigated. $S=$ secondary inflorescence stage, $\mathrm{T}=$ tertiary inflorescence stage, $\mathrm{Q}=$ quaternary inflorescence stage.

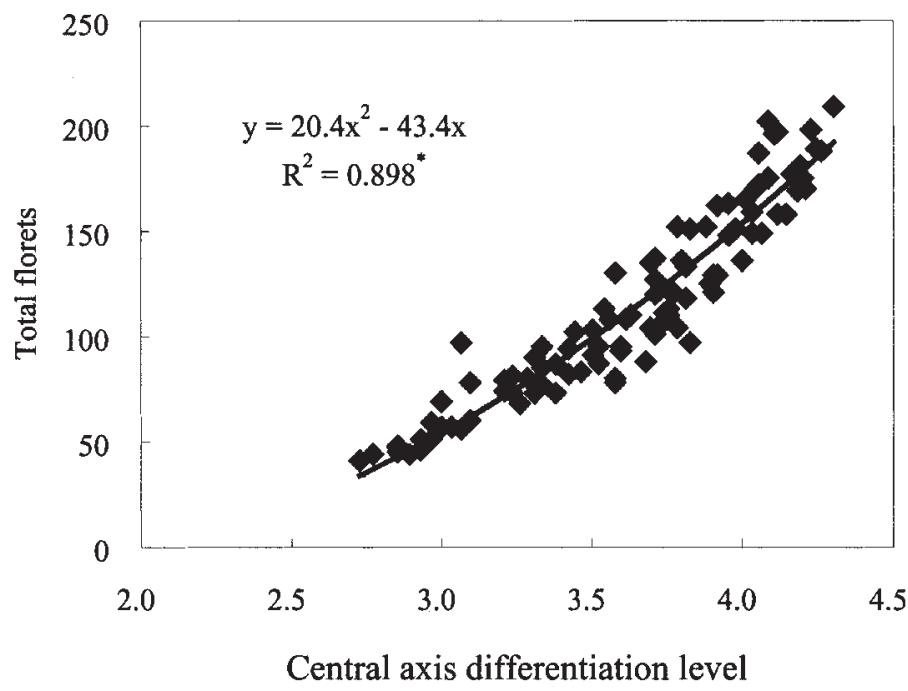

Fig.8. Relationship between total floret number and differentiation level (quantitative description of differentiation stage) of central axis. $* R^{2}$ significant at the $5 \%$ level.

evocation to anthesis) takes about four to five months, depending on temperature, light intensity, nutrition, floret number of an inflorescence, etc. This explains the observation for a four-month flowering process (Fig. 5).

Photoperiod was not considered a factor affecting the flowering of chinese ixora in our study. Sakai and Higuchi (1980) experimented with 8 and 16-h photoperiods on chinese ixora and found no difference between short and long photoperiods. Shillo and Tsook (1989) pointed out that chinese ixora does not respond to photoperiod. Chen and Huang (1996) also reported that a $4 \mathrm{~h}$ night break from 1000 to $0200 \mathrm{HR}$ did not influence the flowering of chinese ixora.

Flowering is the first step toward sexual reproduction in plants. The onset of flowering is greatly influenced by the environment. The study of the floral differentiation processes and the chronology of vegetative and flowering sequence of chinese ixora in this paper has provided an explanation for the following phenomenon: After the ability to flower has been attained, chinese ixora could flower almost all year round in southern Taiwan. Full anthesis occurs between January and May but flowering can occur sparsely in other seasons (Chen and Huang, 1996). In northern Taiwan, only single full anthesis occurs in June through September (Chang and Wu, 1997). 


\section{Literature Cited}

Bernier, G., J-M. Kinet, and R.M. Sachs. 1981a. The initiation of flowers, p. 3-12, 106-115. In: The physiology of flowering. vol 1.CRC Press, Boca Raton, Fla.

Bernier, G., J-M. Kinet, and R.M. Sachs. 1981b. Transition to reproductive growth, p. 22-34, 78-90, 179-182. In: The physiology of flowering. vol 2. CRC Press, Boca Raton, Fla.

Chang, Y.S. and S.C. Wu. 1997. The flowering habits of Ixora spp. and effects of pruning time on the growth and flowering in Ixora williamsii cv. Sunkist. J. Chinese Soc. Hort. Sci 43:330-340.

Chen, L.Y. and M.C. Huang. 1996. Effects of shading and winter heating on growth and flowering of Ixora chinensis Lam. J. Agr. Assn. China (New Ser.) 174:72-82.

Chen, T.S. and T.W. Hu. 1976. Ixora, p. 250 (in Chinese). In: A list of exotic ornamental plants in Taiwan. Chuan-Liu Press, Taipei, Taiwan, R.O.C.

Graf, A.B. 1985. Ixora, p.2015, 2324. In: Exotica Series 4, vol II. 12th ed., Roehrs Co., East Rutherford, N. J.

Graf, A.B. 1986. Ixora, p.868, 1024. In: Tropica, 3rd ed., Roehrs Co., East Rutherford, N. J.

Griffiths, M. 1994. Glossary, p. xxxiii, xxxv, xliv. In: A. Huxley (ed.). The RHS index of garden plants. Macmillan Press, London.

Kinet, J-M., R.M. Sachs, and G. Bernier. 1985. The development of flowers, p. 2-42. In: The physiology of flowering. vol 3. CRC Press, Boca Raton, Fla.

Litlere, B. and E. Stromme. 1975. The influence of temperature, daylength, and light intensity on flowering in Hydrangea macrophylla (Thunb.) Ser. Acta Hort. 51:285-298.

Liu, T.S. 1962. Ixora, p. 1111 (in Chinese). In: Illustrations of native and introduced ligneous plants of Taiwan. vol 2. Agr. Ser. No. 8, National Taiwan Univ. Press, Taipei, Taiwan, R.O.C.

Liu, Y.C., F.Y. Lu, and C.H. Ou. 1988. Ixora, p. 734-736 (in Chinese). In: Trees of Taiwan. Monogr. Publ. No. 7, College of Agr., National Chung Hsing Univ., Taichung, Taiwan, R.O.C.

Morioka, K.T., T. Sakasita, and K. Yonemura. 1989. Effects of minimum temperature on flowering time and uniformity of Ixora chinensis Lam. Res. Bul. Aichi Agr. Res. Ctr. 21:225-229.

Porter, C.L. 1967. Phytography and its terminology (Inflorescence), p. 96-101. In: Taxonomy of flowering plants. 2nd ed. W.H. Freeman, San Francisco.

Sakai, K. and H. Higuchi. 1980. Effects of temperature, photoperiod and time of pinching on flowering of chinese Ixora (Ixora chinensis Lam.) Res. Bul. Aichi Agr. Res. Ctr. 12:109-113.

Shillo, R. and H. Tsook. 1989. Ixora, p. 379-386. In: A.H. Halevy (ed.). CRC Handbook of flowering. vol 6. CRC Press, Boca Raton, Fla.

Whistler, W.A. 2000. Ixora, p. 276-280. In: Tropical ornamentals. Timber Press, Portland, Ore. 